\title{
Análise do desflorestamento no entorno de um assentamento na região de Aripuanã- MT
}

\author{
Analysis of deforestation around a settlement in the region of Aripuanã - MT \\ Análisis de deforestación alrededor de un asentamiento en la región de Aripuanã - MT
}

Recebido: 07/07/2021 | Revisado: 10/07/2021 | Aceito: 12/07/2021 | Publicado: 23/07/2021

\author{
Giselle Cristina da Costa \\ ORCID: https://orcid.org/0000-0002-9245-6544 \\ Universidade Estadual do Mato Gosso, Brasil \\ E-mail: gicristina1512@gmail.com \\ Rosiane Alexsandra dos Santos Costa \\ ORCID: https://orcid.org/0000-0002-7203-3907 \\ Universidade Estadual do Mato Gosso, Brasil \\ E-mail: rosianecosta22@gmail.com \\ Jackson Ferreira da Silva \\ ORCID: https://orcid.org/0000-0002-0318-4453 \\ Universidade Estadual do Mato Gosso, Brasil \\ E-mail: jackagro13@gmail.com \\ Luiz CláudioAlmeida Martins \\ ORCID: https://orcid.org/0000-0003-2967-2129 \\ Universidade Estadual do Mato Gosso, Brasil \\ E-mail: claudinhomrtins_almeida@hotmail.com \\ Solange Aparecida Arrolho da Silva \\ ORCID https://orcid.org/0000-0002-8038-1303 \\ Universidade Estadual do Mato Gosso, Brasil \\ E-mail: solange.arrolho@unemat.br
}

\begin{abstract}
Resumo
A implantação de um assentamento pode acarretar mudanças no uso e cobertura da terra, gerando uma série de impactos sociais, econômicos e ambientais. $\mathrm{O}$ entendimento destes processos pode permitir um melhor planejamento de políticas públicas a fim de monitorar e mapear áreas mais suscetíveis a problemas ambientais. Até a atualidade não existe registrado um acompanhamento técnico e uma rotina de avaliação dos resultados dos projetos de assentamento de reforma agrária implantados. Este trabalho teve como objetivo analisar a área de entorno de $30 \mathrm{~km}$ do Assentamento Medalha Milagrosa, localizado ao norte de Mato Grosso, a fim de verificar se as alterações na região são decorrentes da criação do Assentamento. Analisou-se arquivos em formato shapefille de 2000 a 2015 disponibilizados pelo projeto PRODES. Os resultados mostraram que entre 2000 e 2005 foram os anos em que a taxa de desflorestamento esteve mais alta. O período em que os números voltam a mostrar elevação foi após a criação do assentamento no ano de 2008 e nos períodos seguintes até 2015 os números apontaram ligeira alteração, mas sempre para menos. Os dados apontam que não só as atividades vinculadas a criação de um assentamento como também as outras diversas atividades irregulares que ocorrem fora da área assentada podem contribuir para o aumento do desflorestamento. Desta forma, é imprescindível que tanto os assentamentos quanto as demais propriedades estejam em conformidade com as leis ambientais, podendo assim garantir um futuro em harmonia com o desenvolvimento agrário sustentável, visando a proteção ao ambiente.
\end{abstract}

Palavras-chave: Desflorestamento; Assentamento rural; Sensoriamento remoto; Reforma agrária.

\begin{abstract}
The implementation of a settlement can lead to changes in land use and coverage, generating a series of social, economic and environmental impacts. Understanding these processes can allow for better planning of public policies in order to monitor and map areas that are more susceptible to environmental problems. To date, there is no record of technical monitoring and a routine for evaluating the results of the implemented agrarian reform settlement projects. This work aimed to analyze the area around $30 \mathrm{~km}$ of the Medalha Milagrosa Settlement, located in the north of Mato Grosso, in order to verify if the changes in the region are due to the creation of the Settlement. Shapefille files from 2000 to 2015 made available by the PRODES project were analyzed. The results showed that between 2000 and 2005 were the years in which the deforestation rate was highest. The period in which the numbers show an increase was after the creation of the settlement in 2008 and in the following periods until 2015 the numbers showed a slight change, but always to a lesser extent. The data show that not only the activities linked to the creation of a settlement, but also the other various irregular activities that take place outside the settled area can contribute to the increase in deforestation. Thus, it is
\end{abstract}


essential that both the settlements and the other properties comply with environmental laws, thus being able to guarantee a future in harmony with sustainable agrarian development, aiming at protecting the environment.

Keywords: Deforestation; Rural settlement; Remote sensing; Land reform.

\begin{abstract}
Resumen
La implementación de un asentamiento puede generar cambios en el uso y cobertura del suelo, generando una serie de impactos sociales, económicos y ambientales. Comprender estos procesos puede permitir una mejor planificación de las políticas públicas para monitorear y mapear áreas más susceptibles a problemas ambientales. A la fecha, no existe un registro de seguimiento técnico y una rutina para evaluar los resultados de los proyectos de asentamiento de reforma agraria implementados. Este trabajo tuvo como objetivo analizar el área en torno a $30 \mathrm{~km}$ del Asentamiento Medalha Milagrosa, ubicado en el norte de Mato Grosso, con el fin de verificar si los cambios en la región se deben a la creación del Asentamiento. Se analizaron los archivos Shapefille de 2000 a 2015 puestos a disposición por el proyecto PRODES. Los resultados mostraron que entre 2000 y 2005 fueron los años en los que la tasa de deforestación fue más alta. El período en el que las cifras vuelven a mostrar un aumento fue después de la creación del asentamiento en 2008 y en los siguientes períodos hasta 2015 las cifras mostraron un ligero cambio, pero siempre en menor medida. Los datos muestran que no solo las actividades vinculadas a la creación de un asentamiento, sino también las otras diversas actividades irregulares que tienen lugar fuera del área poblada pueden contribuir al aumento de la deforestación. Por ello, es fundamental que tanto los asentamientos como las demás propiedades cumplan con las leyes ambientales, pudiendo así garantizar un futuro en armonía con el desarrollo agrario sostenible, con el objetivo de proteger el medio ambiente.
\end{abstract}

Palabras clave: Deforestación; Asentamiento rural; Detección remota; Reforma agraria.

\title{
1. Introdução
}

A concentração de terras no Brasil resultou na exclusão social e territorial de uma ampla parte da população; a luta pela terra vem se destacando no contexto nacional pressionando o governo a adotar políticas públicas, dando enfoque cada vez mais ao desenvolvimento socioeconômico da população sem-terra, dessa forma se faz necessário a reestruturação fundiária do país com objetivo de reformular a divisão de terras (Rodrigues; Silva \& Moreira, 2008).

Com a criação do Instituto Nacional de Colonização e Reforma Agrária (INCRA) em 1970, muitas áreas do estado de Mato Grosso foram federalizadas, e 60\% das terras matogrossenses passou a ser de encargo do INCRA. Baseado no Estatuto de Terras (Lei no 4.504/1964), este órgão passou a promover a distribuição de terras para colonização oficial e particular, visando a povoação da Amazônia (Lamera \& Figueiredo, 2008).

A Lei $n^{\circ}$ 13.465/2017 por sua vez, propõe outorgar o título definitivo aos assentamentos mais antigos independentemente da situação em que se encontram em termos de infraestrutura produtiva e condições de sobrevivência das famílias assentadas (Pereira, 2018).

Segundo o INCRA (2020), o assentamento rural é um conjunto de unidades agrícolas independentes entre si, instaladas onde originalmente existia um imóvel rural que pertencia a um proprietário, e cada uma dessas unidades é entregue a uma família de agricultores sem condições econômicas de adquirir ou manter um imóvel rural. De acordo com o órgão, o assentamento possui unidades produtivas e de moradia, comportando também áreas comunitárias e espaços para construção de estruturas de uso coletivos, como igrejas, sede de associações, escolas e áreas esportivas, e áreas de preservação ambiental.

O objetivo da reforma agrária é cumprir com a implantação de um assentamento baseado na viabilidade econômica, na sustentabilidade ambiental e no desenvolvimento territorial (Aguilar et al., 2011). Portanto é necessário a caracterização do assentamento, que é um trabalho técnico descritivo que reúne e espacializa através de mapas as informações georreferenciadas, e tem por finalidade subsidiar a discussão para formulação das propostas para elaboração do Plano de Desenvolvimento dos Assentamentos (PDAs) (Francisco et al., 2012).

Sendo o INCRA a autarquia responsável pela Reforma Agrária e o Ordenamento Fundiário no Brasil, Figueredo (2019) assevera que "[...] é necessário que o órgão faça a correção do fluxo das ações e programas até então executados, a fim de dá-los andamento sem se desvirtuar dos objetivos definidos para essa política". 
Os assentamentos que foram criados pelo INCRA no passado muito contribuíram para aumentar o grave problema de impacto ambiental. Em consequência de algumas atividades como a agrossilvicultura, agrossilvipastoril, agricultura de baixo impacto ambiental entre outros, realizados sem critérios técnicos ou sem considerar o uso alternativo do solo através de sistema de produção sustentável, os assentamentos rurais apresentam alto índice de desmatamento, seja em área de preservação permanente, seja em área que poderia ter sido destinada a constituição da reserva legal (Barroso, 2014).

O termo assentamento está relacionado a um espaço preciso em que uma população será instalada sendo, portanto, uma transformação do espaço físico, cujo objetivo é a sua exploração agropecuária. Assim, é necessário compreender de que modo os espaços se modificam na medida em que os assentamentos se constroem (Souza; Ramirez \& Bergamasco, 2007).

Os Sistemas de Informação Geográfica (SIG) estão cada vez mais oferecendo uma maneira rápida para realizar trabalhos visando à gestão dos recursos naturais, tornando possível a análise espacializada no desenvolvimento de modelos e cenários para apoio à decisão, como análises de viabilidade, de tendências, de vulnerabilidade, de risco ou de impactos ambientais (Sarmento et al., 2008). Um sistema de geoprocessamento permite registrar geograficamente os limites das parcelas rurais e individualizadas (assentamentos) e criar um banco de dados cadastrais e socioeconômicos, além de possibilitar a espacialização dos dados em um mapa (Aguiar et al., 2003).

As fontes de desflorestamento seriam as ações dos agentes do desflorestamento, como agricultores, pecuaristas, madeireiros e grandes áreas de plantio (Rodrigues, 2004).

De acordo com Leal e Maniese (2018), ainda que se encontre relações na literatura, ainda não se pode afirmar a existência de relações entre a política dos assentamentos e a prática de desflorestamento, visto que este é um passivo ambiental em si sendo o mesmo influenciado pela própria legislação do INCRA, assim como a Instrução Normativa $n^{\circ} 3$, de 8 de setembro de 1992, que citava a desapropriação de florestas nativas com ausência de produção. Assim, regido pela influência da política do INCRA no processo de desflorestamento, bem como a falta de infraestrutura e de assistência técnica, a ausência de crédito e perda de safra dos beneficiários, juntamente com a ocupação ilegal de terras, são fatores que também auxiliam a prática predatória dos recursos naturais. Neste sentido, o autor afirma que, uma das possíveis medidas de controle do desflorestamento é a regularização fundiária visto que, segundo este, cerca de 53\% das terras da região amazônica não possuem definição fundiária (Leal \& Maniese, 2018).

O processo de desmatamento por corte raso é aquele que resulta na remoção completa da cobertura florestal em um curto intervalo de tempo. Nesse processo, a cobertura florestal é totalmente removida e substituída por outras coberturas e usos (agrícola, pastagem, urbano, hidroelétricas etc.) (Inpe, 2013). Diante das modificações que os assentamentos podem causar no espaço físico do meio rural esta pesquisa analisou a partir de Sistemas de Informações Geográficas (SIGs) as ocorrências de desflorestamento entre os anos de 2000 a 2015 e buscou responder ao seguinte questionamento: a criação do assentamento interfere nas características da paisagem? O estudo parte da hipótese de que a posse da terra efetivada pode causar com o passar do tempo grandes alterações ambientais na área do assentamento e ao seu entorno. Assim, estabeleceu-se como objetivo geral da pesquisa analisar se essas alterações são advindas da criação do assentamento.

Destaca-se o objetivo e pauta como de grande relevância, pois com o desflorestamento, modifica-se a base da cadeia trófica, desestabilizando o fluxo de energia e estímulo a evasão faunística, compromete a variabilidade genética e, consequentemente, a biodiversidade.

\section{Metodologia}

\subsection{Caracterização da área de estudo}

A realização da pesquisa acerca do tema abordado deu-se de natureza quantitativa e qualitativa. Segundo Pereira et al (2018), os métodos qualitativos buscam descrever as interpretações do pesquisador sobre um determinado fenômeno. O que se 
torna imprescindível também a coleta de dados, as quais ao serem obtidos foram organizados de maneira sistêmica de forma a permitir uma análise e compreenção dos resultados alcançados.

O objeto selecionado para o desenvolvimento deste estudo foi uma área de entorno de $30 \mathrm{~km}$ do Assentamento Medalha Milagrosa, abrangendo municípios de Aripuanã, Colniza, Cotriguaçu e Juruena, do estado de Mato Grosso, com uma extensão territorial de aproximadamente 528.694 hectares, entre as coordenadas $9^{\circ} 51$, "S e $10^{\circ} 34^{\prime}, " \mathrm{~S}$ de latitude sul e $59^{\circ} 12$, "W e 59¹1',"W de longitude oeste. A área é cortada pela BR 174/MT418, MT 420, MT 208 e MT 183 (Figura 1).

Figura 1: Localização geográfica da área de estudo, ao norte do estado do Mato Grosso.

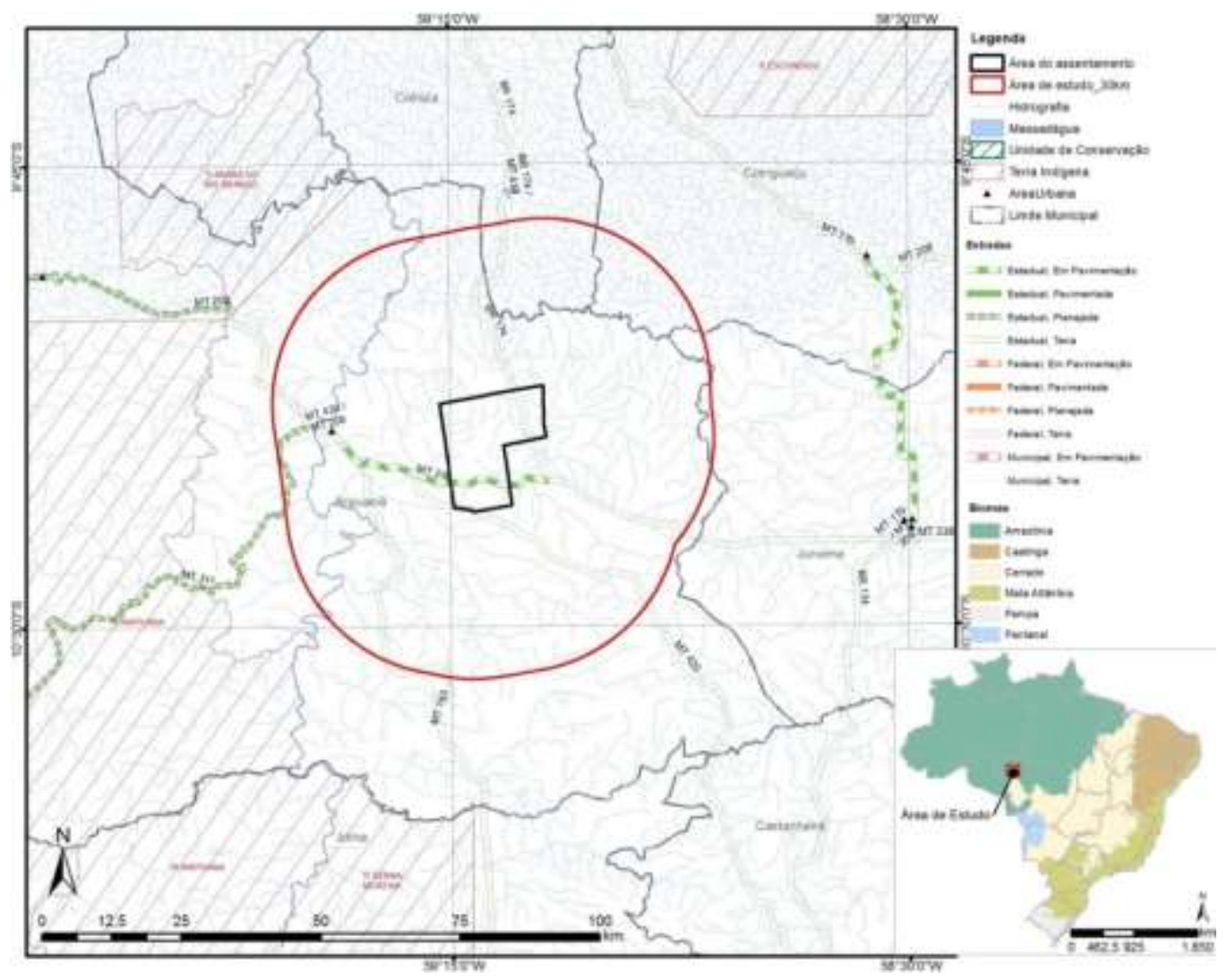

Fonte: Autoria própria (2016).

A Figura 2 mostra a distribuição percentual dos municípios que compõem a área de estudo, sendo Aripuanã o município com maior área contemplada pela delimitação de $30 \mathrm{~km}$, cerca de $89 \%$. 
Figura 2: Distribuição percentual dos municípios que compõem a área de estudo.

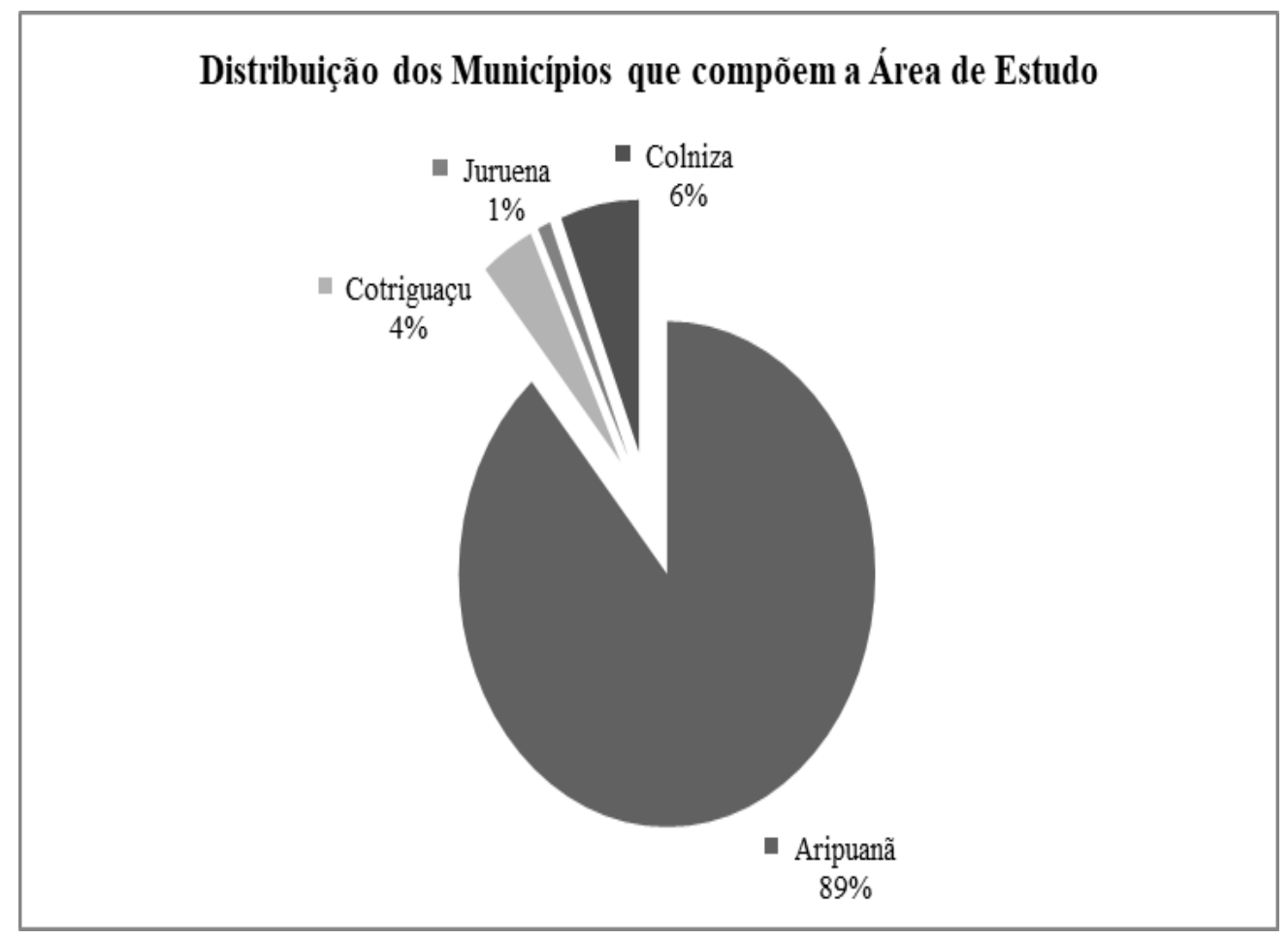

Fonte: Autoria própria (2016).

A área de estudo está inserida na bacia hidrográfica do rio Aripuanã, à margem direita do rio Madeira, pertencente à Região Hidrográfica Amazônica, uma das 12 Divisões Hidrográficas estabelecidas pelo Conselho Nacional de Recursos Hídricos - CNRH. O período chuvoso na bacia compreende os meses de novembro a março, com o trimestre mais chuvoso abrangendo os meses de dezembro a fevereiro ou janeiro a março, dependendo da posição latitudinal. A estiagem inicia-se em abril e estendese até outubro, com os meses mais secos no trimestre de junho a agosto (Brasil, 2011).

Os municípios apresentam baixa antropização e estão inseridos em uma região do estado com forte característica amazônica, predominantemente recoberta pela Floresta Ombrófila (Amazônica) associada com a Floresta Estacional em cerca de 50\% da área e com Savanas. A substituição das florestas para instalação de pastagens, ocasionando a fragmentação dos ambientes, é verificada principalmente nas proximidades de Colniza, Cotriguaçu e Juruena. Já no município de Aripuanã as áreas mais alteradas encontram-se no seu entorno, devido à retirada seletiva de madeira e aos desmatamentos para a instalação de pastagem para criação extensiva de gado. Nas áreas já apropriadas predominam atividades desenvolvidas com manejos de nível tecnológico médio, verificando-se tanto a presença de grandes fazendas voltadas à pecuária quanto de núcleos de pequenos e médios produtores voltados a uma policultura diversificada, com tendência a pecuarização (Geominas, 2015).

A dinâmica de ocupação do município de Aripuanã é marcada pela formação de novos núcleos urbanos a partir de assentamentos, de pontos de passagem ou crescimento de vilas rurais no sentido de transformá-las em sedes urbanas de distritos e, posteriormente, em municípios.

O assentamento Medalha Milagrosa é caracterizado como PA (Projeto de Assentamento) na modalidade convencional, surgido através da ocupação de uma fazenda de propriedade privada chamada Nossa Senhora Medalha Milagrosa, por grupos de produtores sem-terra. Trata-se de área onde era explorada a madeira nativa e na época da ocupação encontrava-se sem nenhum tipo de utilização. Segundo Lima e Zoemer (2011) foi o proprietário das terras que incentivou a ocupação pelos trabalhadores rurais, tendo em visto o seu interesse em vender essas terras para o governo federal. Com extensão de 27.464 hectares, ao todo foram demarcados 400 lotes de 50 hectares cada, os quais foram distribuídos um para cada família. A área foi desapropriada 
pelo INCRA em 07 de novembro de 2007, contudo, até hoje os produtores rurais aguardam os procedimentos para a regularização e formalização da posse das terras. O processo se encontra paralisado devido à falta de recursos para fazer a topografia e o georreferenciamento das terras conforme informam os técnicos do INCRA.

\subsection{Procedimentos Metodológicos}

Para cumprir com o objetivo proposto, utilizou-se os dados do PRODES, projeto do Instituto Nacional de Pesquisas Espaciais (INPE), que realiza o monitoramento por satélite do desmatamento por corte raso na Amazônia Legal e produz, desde 1988, as taxas anuais de desmatamento na região, que são usadas pelo governo brasileiro para o estabelecimento de políticas públicas (INPE, 2016).

Obteve-se do PRODES os arquivos em formato Shapefile e Geotiff dos anos de 2000 a 2015, órbita/ponto 229/067, pois esta contempla a área de estudo escolhida. Delimitou-se uma área de entorno de $30 \mathrm{~km}$ do assentamento.

Para interpretação dos arquivos Shapefile utilizou-se o pacote de software ArcGIS 10.2, conforme Umbelino et.al (2007) esse programa possui aplicativos e ferramentas que possibilitam delimitar e quantificar as dinâmicas temporais de um dado local do qual se quer obter informações.

Os dados obtidos estavam sem um sistema de referência ou na projeção SAD69 (South American Datum 1969). Para adequação dos arquivos utilizou-se o software Global Mapper V.13 que permite readequar os arquivos na projeção escolhida.

Coordenadas como latitude, longitude e altitude, necessitam de um sistema geodésico de referência para sua determinação. Desde 25 de fevereiro de 2015, o SIRGAS 2000 (Sistema de Referência Geocêntrico para as Américas) é o único sistema geodésico de referência oficialmente adotado no Brasil. Entre 25 de fevereiro de 2005 e 25 de fevereiro de 2015, admitiase o uso, além do SIRGAS 2000, dos referenciais SAD 69 e Córrego Alegre. O emprego de outros sistemas que não possuam respaldo em lei, pode provocar inconsistências e imprecisões na combinação de diferentes bases de dados georreferenciadas (Ibge, 2015).

Com auxílio da ferramenta do software ArcGIS "Clip", obteve-se somente os arquivos existentes dentro da área de entorno de $30 \mathrm{~km}$. Em seguida utilizou-se a ferramenta "Calculate Geometry", obtendo o total de cada área desflorestada dos anos 2000 a 2015. Para confecção dos mapas foi utilizado o sensor TM/LandSat8. A partir desses dados foram emitidas tabelas, gráficos e gerados mapas para análise dos resultados.

\section{Resultados e Discussão}

Os arquivos relativos ao ano 2000 referem-se ao desmate total e disponibilizam informações de desflorestamento englobando desmates que ocorreram desde 1998 até o ano 2000, com mais de 35.000 hectares (ha) de área desflorestada. No mesmo âmbito, arquivos referentes ao desflorestamento ocorridos entre os anos 2000 e 2015 (Tabela 1), asseguram referências com um total de mais de 130.000 ha de área de desflorestamento acumulado. 
Research, Society and Development, v. 10, n. 9, e16710917979, 2021

(CC BY 4.0) | ISSN 2525-3409 | DOI: http://dx.doi.org/10.33448/rsd-v10i9.17979

Tabela 1: Desflorestamento ocorridos entre os anos 2000 a 2015.

\begin{tabular}{c|c|c|c}
\hline Ano & $\begin{array}{c}\text { Desflorestamento (área } \\
\text { de estudo) }\end{array}$ & Desflorestamento (acumulado) & $\begin{array}{c}\text { Desflorestamento (área do } \\
\text { assentamento) }\end{array}$ \\
\hline 2000 & $35.268,37$ & & $3.819,24$ \\
2001 & $11.808,67$ & $47.077,04$ & $1.110,68$ \\
2002 & $19.995,26$ & $67.072,30$ & $2.465,54$ \\
2003 & $17.693,35$ & $84.765,65$ & $1.634,13$ \\
2004 & $12.912,46$ & $97.678,10$ & $1.420,08$ \\
2005 & $14.911,97$ & $112.590,08$ & $2.246,40$ \\
2006 & $2.247,99$ & $114.838,07$ & 619,60 \\
2007 & $3.830,78$ & $118.668,84$ & 880,34 \\
2008 & $5.577,69$ & $124.246,53$ & $1.860,52$ \\
2009 & $1.541,28$ & $125.787,81$ & 526,23 \\
2010 & $1.378,44$ & $127.166,25$ & 726,01 \\
2011 & 847,01 & $128.013,26$ & 423,69 \\
2012 & 300,77 & $128.314,03$ & 153,54 \\
2013 & 805,88 & $129.119,91$ & 475,37 \\
2014 & 557,56 & $129.677,47$ & 273,35 \\
2015 & 694,12 & $130.371,59$ & 246,71 \\
\hline
\end{tabular}

Fonte: Autoria própria (2016).

Pesquisas feitas pelo Instituto de Pesquisa Ambiental da Amazônia - IPAM (2016), relatam as diferentes fases que acompanharam o histórico da reforma agrária no Brasil É possível correlacionar esses dados com os altos índices de desmatamentos ocorridos na área de estudo até 2000, principalmente entre 1998 e 2000, que foi caracterizado como início da terceira fase do processo de reforma agrária no Brasil, onde se dava o início das ocupações da terra (Figura 3). Os desmates eram incentivados pelo governo, já que eram condicionantes para assegurar a posição de assentado, de forma que pudessem produzir a partir da substituição da floresta por cultivos agrícolas. Isso pode ter influenciado no fato de ocorrer alto nível de desflorestamento na área de estudo. 
Figura 3: Evolução da criação de assentamento no Brasil.

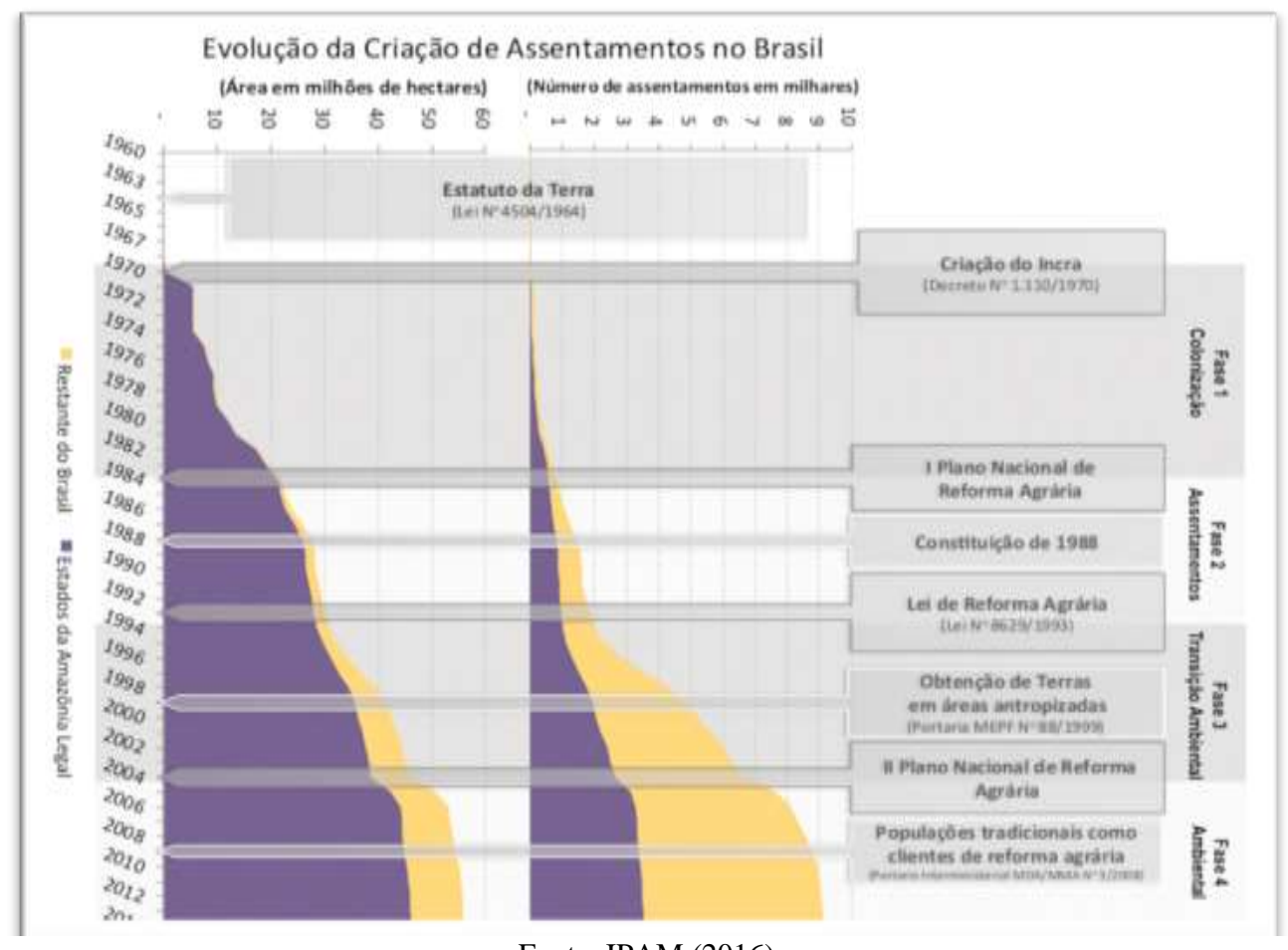

Fonte: IPAM (2016).

Nota-se que de 2001 até 2005 os índices de desflorestamentos continuaram a ser elevados chegando a atingir 14.000 hectares no ano (Figura 4), podendo estar relacionado com as atividades de extração de madeira e pecuária na região. De acordo com o engenheiro agrônomo Heiji da Silva Kawatake, responsável pela Secretaria Municipal de Agricultura de Aripuanã/MT, até o ano de 2006 a principal atividade produtiva da região era a extração de madeira, a qual empregava grande parte da população tanto nas atividades de extração quanto no beneficiamento de madeira.

Figura 4: Relação dos desflorestamentos ocorridos dentro da área de estudo ao longo dos anos.

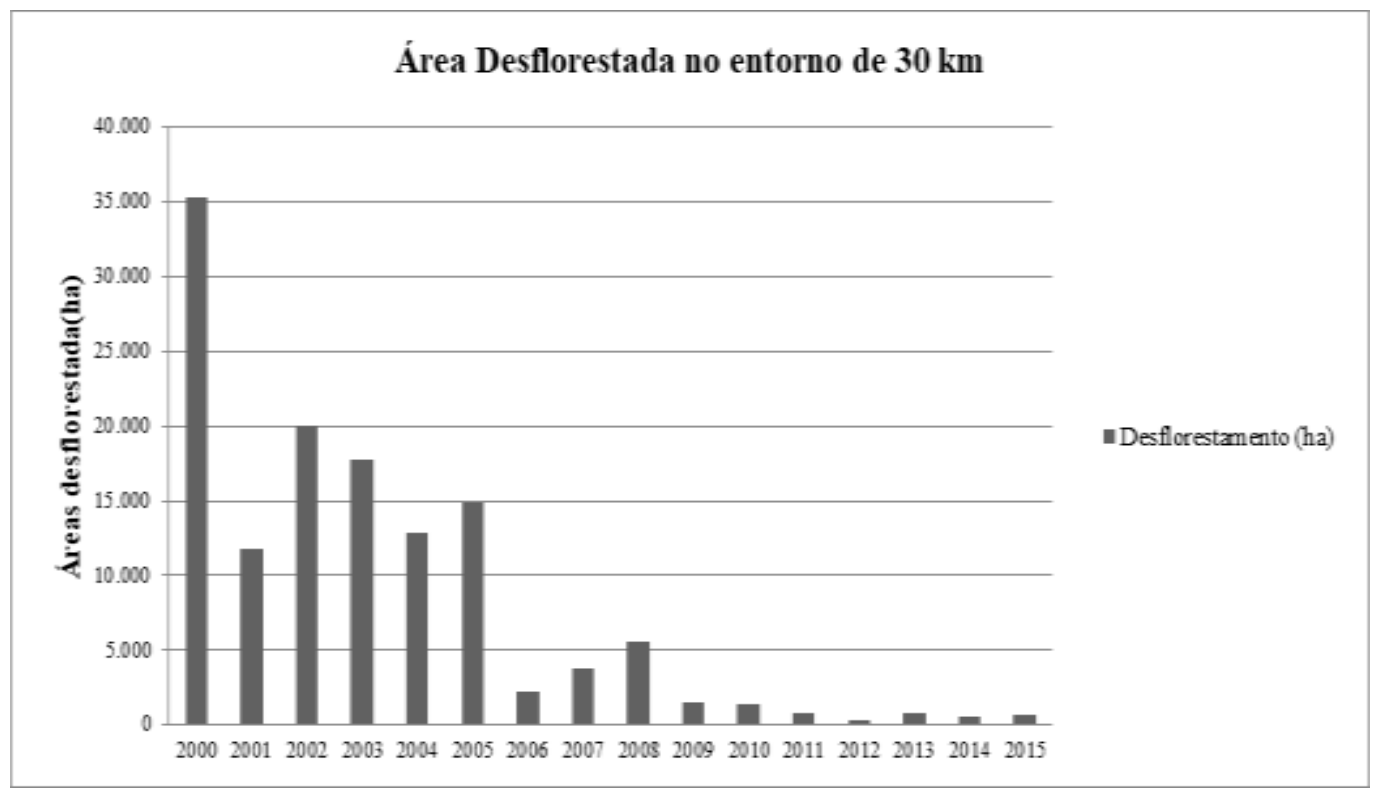

Fonte: Autoria própria (2016). 
Essas atividades indevidas dos recursos naturais fizeram com que entidades como a Polícia Federal e Instituto Brasileiro do Meio Ambiente e dos Recursos Naturais Renováveis (IBAMA), colocassem em prática a operação Arco de Fogo, cujo objetivo principal foi uma rigorosa fiscalização na retirada de madeira. Esta operação levou ao fechamento de diversas indústrias madeireiras que atuavam de forma irregular na cidade, gerando assim problemas sociais e econômicos, como por exemplo, a saída de muitas famílias de Aripuanã/MT para outras cidades. Com o objetivo de minimizar os problemas sociais e econômicos da região, surgiu a operação Arco Verde, visando promover novas oportunidades econômicas para o a localidade, principalmente através de programas cuja finalidade era apoiar a agricultura familiar, contribuindo para a geração de renda na atividade, evitando o êxodo rural e promovendo a preservação ambiental.

No entanto, fazendo uma comparação entre a área total delimitada para o estudo e a área do assentamento Medalha Milagrosa e os desflorestamentos ocorridos os números mostram que a partir de 2006 o desmate na área de estudo representa $30 \%$ ou mais do desflorestamento de toda a região (Figura 5).

Figura 5: Comparação da equivalência de desflorestamento em porcentagem entre a área do assentamento e a área de entorno.

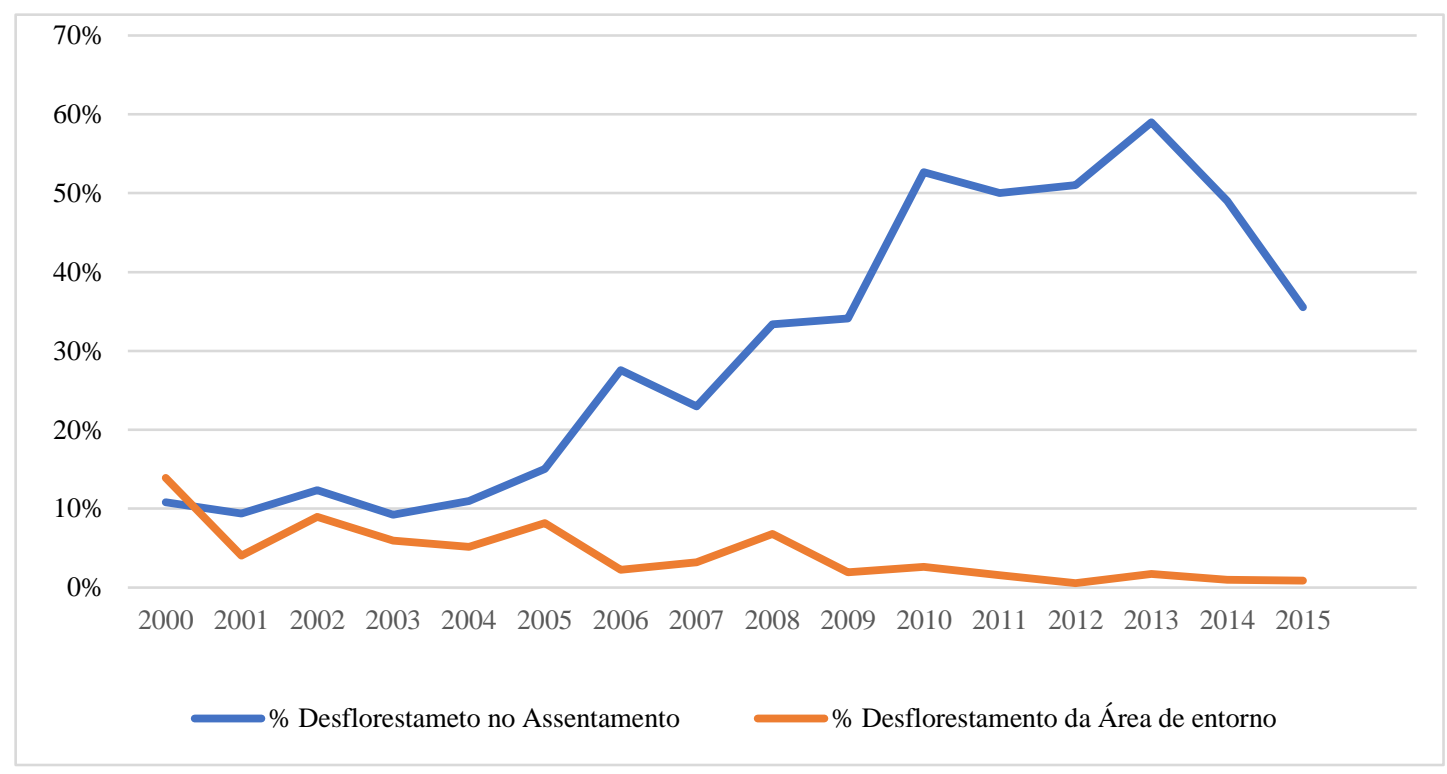

Fonte: Autoria própria (2016).

A ocorrência de desflorestamento diminuiu na área de entorno em 2006, algo em torno de 2.240 hectares, talvez em resposta aos programas de incentivo rural que estavam sendo implantados pelo INCRA, como o Programa Assentamentos Verdes (PAV), que iniciou nesse ano, que estabelecia procedimentos para o licenciamento ambiental em assentamentos de reforma agrária, e tinha por meta estancar o desmatamento nessas áreas (Incra, 2012). De acordo com o órgão, o PAV consiste num programa do INCRA que visa a valorização de atividades produtivas, recuperação de passivos ambientais, geração de renda e regularização fundiária e ambiental através do Cadastro Ambiental Rural - CAR.

O Assentamento criado pelo INCRA no final 2007 e em 2008 os índices indicam outra elevação nos dados de desflorestamento atingindo uma área de 5.577 hectares, podendo indicar que as recentes atividades realizadas nos assentamentos oriundas de sua criação fizeram elevar tais índices. As fases de consolidação dos assentamentos são importantes indicadores do impacto da política de reforma agrária para a fixação do homem no campo e melhoria da qualidade de vida das famílias assentadas (Incra, 2012). Uma vez instalado no seu lote, o agricultor é o ator principal do seu território, através dos diferentes usos do solo que ele define. As suas escolhas no que concerne à divisão do espaço, o grau de intensificação da produção, o uso 
do fogo e a conservação do espaço natural florestal, dependem de vários fatores, tais como as tendências do mercado agrícola, o acesso a créditos e a legislação ambiental.

Nos anos seguintes (2009 e 2010) houve uma queda nos indicativos. O ano de 2012 se destaca por apresentar menor índice de desflorestamento desde 2000. Pesquisa feita no assentamento em 2011 relata alta evasão de alguns membros das famílias, geralmente de jovens. Segundo a pesquisa os jovens geralmente já não residem mais no local indo morar na área urbana, ficando nos assentamentos apenas os pais e crianças, ocasionando falta de mão-de-obra para trabalhar na propriedade, podendo também ser um dos motivos de baixo desflorestamento (Lima \& Zomer, 2011).

Em 2013 pode-se observar uma elevação no desflorestamento principalmente dentro do assentamento com relação ao ano anterior. Ainda conforme a pesquisa aplicada no local os produtores vindos de outras regiões (geralmente do sul do país) não conseguem aplicar as mesmas técnicas de agricultura que utilizavam em suas regiões anteriores, ocasionado uma produção ruim, levando a desistir da agricultura e criar gado de corte. Geralmente estas famílias compram até dois lotes no assentamento. Dessa maneira, alguns objetivos políticos e do uso social da terra acabam sendo violados, pois ocorre uma comercialização das terras e são destinadas a criação de gado de corte. Essa atividade quando realizada de maneira descontrolada acarreta em grandes problemas ambientais, pois para criação de bovinos é necessário a substituição da vegetação nativa por pastos e muitas vezes ocorre o desmatamento também em áreas de nascentes próximas aos cursos d'água.

Dados secundários relatam que as principais atividades desenvolvidas nos assentamentos são a agricultura, que responde por $31 \%$ das atividades, $19 \%$ praticam somente a pecuária, e $50 \%$ as duas atividades. Vale enfatizar que os produtores que criam gado de corte, são os que possuem área de 100 hectares ou mais.

Outro indicativo para aumento da taxa de desflorestamento em 2013 foi que o desmatamento na área florestal de Mato Grosso aumentou 52\% com relação ao mesmo período do ano anterior. E o município de Aripuanã, onde está inserida maior parte da área delimitada, apareceu na lista do Ministério do Meio Ambiente (MMA), como um dos municípios que mais desmataram nesse período (Ferreira, 2013).

Em geral, os colonos assentados apresentam-se aptos para a atividade da chamada agricultura familiar, cujas características de ocupação mantêm o sistema de derrubada da mata existente nos lotes adquiridos e o subsequente plantio de sementes de arroz junto com brachiária (capim predominante). Desse sistema a pecuária é a atividade sequencial, decorrente do baixo investimento e da alocação no processo de animais sem origem ou outros aspectos tecnológicos, instalados em pastos de baixo rendimento. $\mathrm{O}$ interesse para o futuro pecuarista é a legitimação e fixação da propriedade, sendo essa prática estimulada pela falta de alternativa para outros processos produtivos, decorrentes da qualidade da terra ou da falta de recursos financeiros ou humanos (Bonjour, 2008).

De acordo com os arquivos analisados, os anos de 2014 e 2015 apresentam baixa atividade em relação ao desflorestamento e ocorreu uma estabilidade entre esses dois últimos anos (Figura 6). Esse dado pode indicar os muitos casos de pequenos agricultores quando avançam sobre a área de reserva legal, na busca de aumentar as áreas para as atividades agrícolas e pecuárias, contribuindo assim com a redução dos remanescentes de vegetação nativa na região e, consequentemente, extinguindo as áreas a serem desmatadas, estabilizando os dados do desflorestamento. Contudo, nessa última década, vem ocorrendo uma mudança de paradigma, principalmente por parte do governo, que tem criado vários dispositivos legais para promover e garantir a qualidade e função ambiental nos projetos de assentamento. 
Figura 6: Índice anual de desflorestamentos e o desflorestamento acumulado. Observa-se que a taxa de desflorestamento anual para toda a região diminui gradativamente ao longo dos anos.

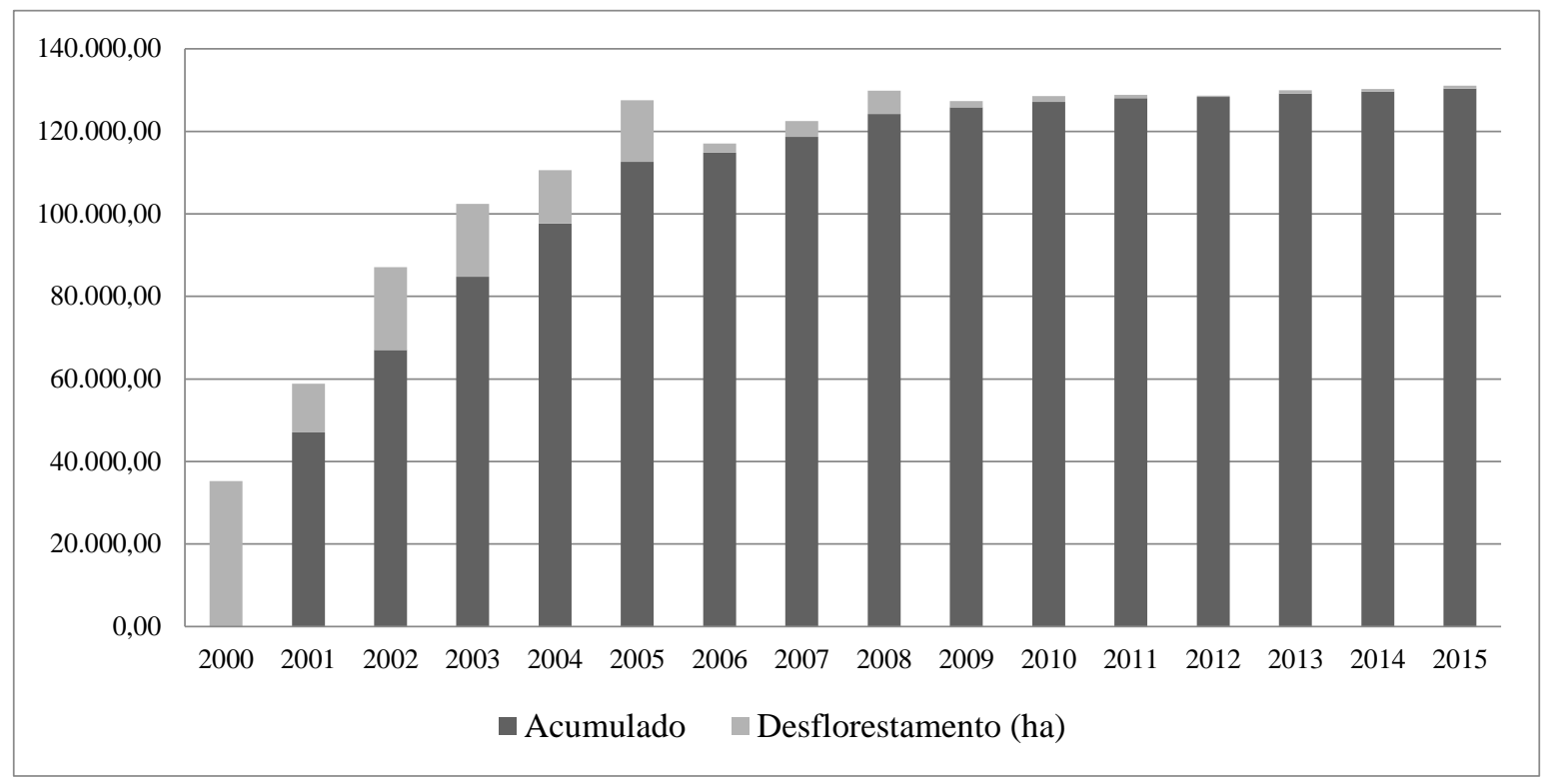

Fonte: Autoria própria (2016).

Por um processo de licenciamento simplificado, os assentados são convocados a realizar procedimentos que visem ao atendimento das obrigações previstas na legislação ambiental abrangendo, inclusive, as situações passíveis de regularização.

A regularização ambiental dos imóveis rurais integrantes de assentamentos de Reforma Agrária é um procedimento previsto na Lei Federal no 12.651, de 25 de maio de 2012 (novo Código Florestal). Essa regularização é realizada através do Cadastro Ambiental Rural, estabelecido pelo art. 29 desta lei, que permitiu “integrar as informações ambientais das propriedades e posses rurais, compondo base de dados para controle, monitoramento, planejamento ambiental e econômico e combate ao desmatamento" (Conama, 2013).

O presente estudo demonstrou uma alta taxa de desflorestamento em 2000, onde foram identificados 35.000 hectares de área desmatada devido ao início do processo de ocupação na região, estimulada por programas governamentais de incentivo a expansão das fronteiras agrícolas. Em 2005 essa taxa continuava a ser elevada: em torno de 14.000 hectares de desflorestamento advindos principalmente da extração de madeira, que respondia pela produtividade econômica da região. Em 2006 houve uma queda nas taxas de desfloramento na área de entorno (somente 2.247 hectares) e aumentou um ano após a implantação do assentamento, chegando a 5.577 hectares, em 2008. Uma comparação feita entre a área total e área do assentamento demonstrou que a partir de 2006 o desmate na área do assentamento representa sempre 30\% ou mais do desflorestamento de toda a região, índice vinculado as atividades realizadas para a implantação do assentamento.

Nos anos subsequentes, ainda que representando um menor intervalo de tempo, as mudanças foram mais sutis na composição e configuração da paisagem. Revelou-se uma diminuição nas taxas de desmatamento, apresentando em 2015 um desflorestamento anual de 694,12 hectares. A redução dos remanescentes de vegetação nativa na região e a criação de leis para regularizar os assentamentos podem ter contribuído para minimizar os desflorestamentos que vinham ocorrendo. Notadamente com a implantação do Cadastro Ambiental Rural, onde os assentados além de ser beneficiados por ganhar maior garantia jurídica com relação ao cumprimento das normas ambientais, podem mudar o perfil que marca os assentados rurais como responsáveis por grande parcela do desmatamento no país (Figura 7). 
Figura 7: Imagem dos desflorestamentos ocorridos na área de estudo dos anos de 2000 e 2015.

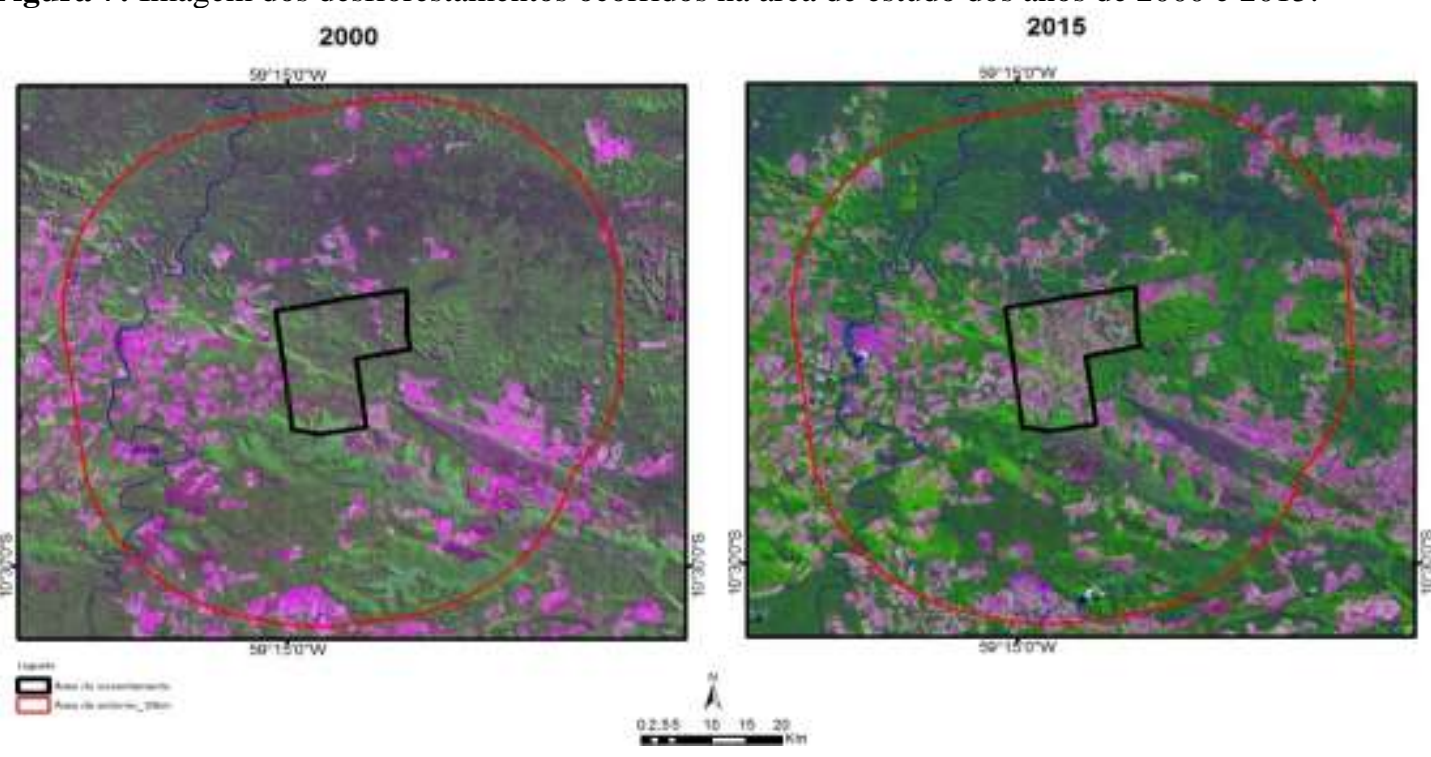

Fonte: Autoria própria (2016).

Concluiu-se que os maiores índices de desflorestamento na área de estudo vêm acontecendo antes da criação do assentamento Medalha Milagrosa, já que após a implantação do assentamento o desflorestamento não avançou. As práticas produtivas e de conversão florestal realizadas pelos assentados afetam principalmente a área do assentamento. Verificou-se que os desflorestamentos são decorrentes de um conjunto de atividades correlacionadas como políticas públicas, instituições, demanda de alimento, renda, população, que juntos agem no desflorestamento do ambiente.

\section{Conclusão}

O presente trabalho procurou descrever a dinâmica de ocupação da área de entorno do assentamento Medalha Milagrosa por meio da análise do uso e cobertura da terra nos anos de 2000 a 2015 disponibilizado pelo PRODES com o intuito de analisar se a criação de um assentamento interfere nas características da paisagem.

Constatou-se que a atividade de corte de madeira na área de entorno de $30 \mathrm{~km}$ acarretou no desflorestamento de aproximadamente de 112.590 hectares da vegetação até 2005, o que pode ser relacionado a atividades de extração madeireira ilegal. Verificou-se que após a implantação do assentamento no ano de 2008 ocorreu aumento nos índices de desflorestamento, em decorrência dos cortes rasos para implantação do assentamento e também da pecuária. Considera-se, portanto, que não só as atividades vinculadas à implantação de um assentamento como também as diversas atividades que ocorrem indiscriminadamente podem contribuir para o aumento do desflorestamento. Como recurso de proteção ao ambiente é imprescindível a adequação não só desses assentamentos como as demais propriedades as leis vigentes, que podem garantir um futuro em conformidade com o desenvolvimento agrário sustentável.

Finalizando considera-se que este trabalho tenha contribuído para o entendimento da dinâmica do desflorestamento frente às políticas públicas e delas decorrentes, já que essa prática compromete a conservação da biodiversidade em seus vários níveis de complexidades.

Em função do dinamismo existente nas atividades nos assentamentos, o que pode ocasionar mudanças significativas na paisagem, recomenda-se o uso do SIG como ferramenta no auxílio da interpretação dos fenômenos que podem ocorrer nos assentamentos, visando a tomada de decisões por parte dos gestores públicos, no que diz respeito ao planejamento de ações, na exploração ou na racionalização de recursos e incremento de projetos. 


\section{Referências}

Aguiar, M. C., Gomes, M. P Lima, S. C. \& Brito, J. L. C. (2003). Integração de dados espaciais de assentamentos de reforma agrária a um banco de dados geográficos e disponibilização na internet utilizando softwares Spring e Spring web. Revista Caminhos de geografia. http://www.ig.ufu.br/caminhos_de_geografia.html.

Aguilar, J. M. R. E., Bitencurti, D. P. \& Gomes, L. J. (2011). Uso do sistema de informações geográficas para análise da sobreposição entre unidades de conservação e assentamentos de reforma agrária em Sergipe. In: Simpósio Regional de Geoprocessamento e Sensoriamento Remoto, 5, Feira de Santana, BH. Anais...Feira de Santana, 418-421. https://www.sigrh.ufs.br/sigaa/verProducao?idProducao=943231\&key=a41965be89cedf60a46ae6c2b49ea59b.

Barroso, L.A. \& Alencar, G. V. (2014). O Cadastro Ambiental Rural (CAR) como instrumento de regularização ambiental em assentamentos de reforma agrária. Revista Brasileira de Gestão Ambiental e Sustentabilidade. http://revista.ecogestaobrasil.net/v1n1/3543-4377-01-02.pdf.

Bonjour, S. C.M., Figueiredo, A. M. R. \& Carvalho, J. M. (2008). A pecuária de corte no estado de Mato Grosso. http://www.sober.org.br/palestra/9/519.pdf.

Brasil, Ministério De Minas E Energia. (2011). Bacia Hidrográfica do Rio Aripuanã. Estudos de inventário hidrelétrico. http://www.epe.gov.br/MeioAmbiente/Documents/AAI\%20Aripuan\%C3\%A3/1\%20-\%20AAI\%20Aripuan\%C3\%A3\%20-\%20Tomo\%201\%20-\%20Texto\% 20-\%20Volume\%20I.pdf.

Conama-Conselho Nacional De Meio Ambiente. (2013). Resolução CONAMA $n^{\circ} 458$, de 16 de julho de 2013. Estabelece procedimentos para o licenciamento ambiental em assentamento de reforma agrária, e dá outras providências. http://www.mma.gov.br/port/conama/res/res13/Resol458.pdf.

Ferreira, J., Micol L., Cézar, C. \& Abad, R. (2012/2013). Análise do desmatamento na área florestal de Mato Grosso em 2012/2013 ICV - Instituto Centro de Vida. http://www.icv.org.br/site/wp-content/uploads/2013/12/Analise-Dematamento-MT-Prodes-2013-ICV.pdf.

Figueredo, C. (2019). A política de assentamento rural executada pelo INCRA: os gargalos na implantação e acompanhamento dos projetos de assentamento. http://repositorio.utfpr.edu.br/jspui/handle/1/4777.

Francisco, P. R. M., Silva, V. D. N., Lima Júnior, R. M. D., Queiroz, E. L. B. D. \& Silva, V. N. (2012). Uso da geotecnologia como ferramenta para a caracterização de assentamentos rurais. Simpósio Regional de Geoprocessamento e Sensoriamento Remoto - Geonordeste, 6, 2012, Aracaju. http://www.dpi.inpe.br/spring/portugues/arquivos_publicacoes/USO\%20DA\%20GEOTECNOLOGIA\%20COMO\%20FERRAMENTA\%20PARA\%20ASS ENTAMENTOS\%20RURAIS.pdf.

Geominas (2015). Projeto Aripuanã/MT: Mina Subterrânea de polimetálicos. http://www.vmetais.com.br/pt. BR/Negocios/ExploracaoMineral/D ocuments/Socioeconomia.pdf.

Ibge - Instituto Brasileiro De Geografia E Estatística. (2015). Sistema geodésico de referência. http://www.ibge.gov.br/home/geocie ncias/geodesia/pmrg/faq.shtm

Incra - Instituto Nacional De Colonização E Reforma Agrária. (2012). Boletim de Análise sobre o Desmatamento em Assentamentos na Amazônia. Assentamentos Verdes, n. 1, http:// www.incra.gov.br/sites/default/files/ uploads/reforma-agraria/análise-balancoe-diagnosticos/boletinsassentamentosverdes/boletim_assentamentos_verdes_n_1_incra_v18_03_2013.pdf.

Incra - Instituto Nacional De Colonização E Reforma Agrária. (2012). Portaria INCRA nº 716, de 27 de novembro de 2012. Institui o Programa Assentamentos Verdes.

http://pesquisa.in.gov.br/imprensa/jsp/visualiza/index.jsp?jornal=1\&pagina=84\&data=28/11/2012. Ac

Incra - Instituto Nacional De Colonização E Reforma Agrária. (2020). Assentamentos da Reforma Agrária. https://www.gov.br/incra/ptbr/@@search?Subject\%3Alist=Assentamento\%20da\%20Reforma\% 20Agr\%C3\%A1ria\%20.

Inpe - Instituto Nacional De Pesquisas Espaciais. Ministério Da Ciência E Tecnologia. (2006). Metodologia para o Cálculo da Taxa Anual de Desmatamento na Amazônia Legal. http://www.obt.inpe.br/prodes/metodologia.pdf.

Inpe - Instituto Nacional De Pesquisas Espaciais. Ministério Da Ciência E Tecnologia. (2016). Monitoramento da Floresta Amazônica por Satélite. Disponível em: http://www.obt.inpe.br/prodes/apresentacao_prodes.pdf.

Inpe - Instituto Nacional De Pesquisas Espaciais. Ministério Da Ciência E Tecnologia E Ministério Do Meio Ambiente. Projetoprodes. (2016). Monitoramento da floresta amazônica brasileira por satélite. Disponível em: http://www.obt.inpe.br/prodes/index.php.

Instituto de Pesquisa Ambiental da Amazônia. (IPAM). (2016). Desmatamento nos Assentamentos da Amazônia -Histórico, tendências e oportunidades. http://ipam.org.br/bibliotecas/desmatamento-nos-assentamentos-da-amazonia-historico-tendencias-e-oportunidades.

Lamera J. A. \& Figueiredo, A. M. R. (2008). Os assentamentos rurais em Mato Grosso. In: Sociedade Brasileira de Economia, Administração e Sociologia Rural-SOBER, Rio Branco - Acre, 20 a 23 de julho de 2008. https://www.researchgate.net/publication/254389124_O s_Assentamentos_Rurais_em _Mato_Grosso.

Leal, M. \& Maniese V. (2018). Dinâmica de desflorestamento nos assentamentos extrativistas do município de Humaitá, Amazonas. Revista de Geografia e Ordenamento do Território (GOT), $n^{\circ} 14$ (setembro). Centro de Estudos de Geografia e Ordenamento do Território, p. 251-266, http://dx.doi.org/10.17127/got/2018.14.010.

Lima, A. F. A. \& Zomer, C. (2011). Condições gerais da organização e da produção em assentamento rural de Aripuanã - MT e o acesso dos produtores aos incentivos e benefícios federais. http://www.convibra.org/upload/paper/adm/adm_2683.pdf.

Pereira, A. S., Shitsuka, D. M., Parreira, F. J. \& Shitsuka, R. (2018). Metodologia da pesquisa científica. UFSM. 
Research, Society and Development, v. 10, n. 9, e16710917979, 2021

(CC BY 4.0) | ISSN 2525-3409 | DOI: http://dx.doi.org/10.33448/rsd-v10i9.17979

Pereira, S. F. (2018). Emancipação de assentamentos rurais: a resistência do MST e os anseios do agronegócio. Revista Equador (UFPI), 7, 62 - 78. https://revistas.ufpi.br/index.php/equador/article/view/7154.

Rodrigues, L. L. M., Silva, A. R. O. \& Moreira, E. R. F. (2008). Da luta por terra à vida na terra: um exemplo do embate entre capital e trabalho no campo. In: Jornada Do Trabalho, IX, 2008, Catalão. Anais..., Catalão: UFG.

Rodrigues, R. L. V. (2004). Análise dos fatores determinantes do desflorestamento na Amazônia legal. http://www.ppe.ufrj.br/index.php/pt/publicacoes/tesese-dissertacoes/2004/1113-analise-dos-fatores-determinantes-do-desflorestamento-na-amazonia-legal.

Sanchéz, L. E. (2008). Avaliação de impacto ambiental - conceitos e métodos, Oficina de Textos, 495 p.

Sarmento. E. C., Flores. C. A., Weber. E. H. \& Pötter, R. O. (2008). Sistema de Informação Geográfica como apoio ao levantamento detalhado de Solos do Vale dos Vinhedos. RS, Brasil. Revista Brasileira de Ciência Do Solo. Https://Doi.Org/10.1590/S0100-06832008000700025.

Souza V. F., Ramirez, G. M. \& Bergamasco, S. M. P. P. (2007). O SIG como uma ferramenta auxiliar da extensão rural. Revista Extensão Rural, DEAER/CPGExR - CCR - UFSM, Ano XIV, 91-108.

Umbelino, G., Sathler, D., Macedo, D. \& Felippe, M. (2007). Aplicação de técnicas de geoprocessamento para a preservação dos recursos hídricos e estudos de vulnerabilidade socioambiental, Anais XII Simpósio Brasileiro de Sensoriamento Remoto, INPE, 5541-5549. 